\title{
Retrieving the Stress Field Within the Campi Flegrei Caldera (Southern Italy) Through an Integrated Geodetical and Seismological Approach
}

\author{
Luca D’Auria, ${ }^{1}$ Bruno Massa, ${ }^{1,2}$ Elena Cristiano, ${ }^{1}$ Carlo Del Gaudio, ${ }^{1}$ Flora Giudicepietro, ${ }^{1}$ \\ Giovanni Ricciardi, ${ }^{1}$ and Ciro Ricco ${ }^{1}$
}

\begin{abstract}
We investigated the Campi Flegrei caldera using a quantitative approach to retrieve the spatial and temporal variations of the stress field. For this aim we applied a joint inversion of geodetic and seismological data to a dataset of 1,100 optical levelling measurements and 222 focal mechanisms, recorded during the bradyseismic crisis of 1982-1984. The inversion of the geodetic dataset alone, shows that the observed ground deformation is compatible with a source consisting of a planar crack, located at the centre of the caldera at a depth of about $2.56 \mathrm{~km}$ and a size of about $4 \times 4 \mathrm{~km}$. Inversion of focal mechanisms using both analytical and graphical approaches, has shown that the key features of the stress field in the area are: a nearly subvertical $\sigma_{1}$ and a sub-horizontal, roughly NNE-SSW trending $\sigma_{3}$. Unfortunately, the modelling of the stress fields based only upon the retrieved ground deformation source is not able to fully account for the stress pattern delineated by focal mechanism inversion. The introduction of an additional regional background field has been necessary. This field has been determined by minimizing the difference between observed slip vectors for each focal mechanism and the theoretical maximum shear stress deriving from both the volcanic (time-varying) and the regional (constant) field. The latter is responsible for a weak NNESSW extension, which is consistent with the field determined for the nearby Mt. Vesuvius volcano. The proposed approach accurately models observations and provides interesting hints to better understand the dynamics of the volcanic unrest and seismogenic processes at Campi Flegrei caldera. This procedure could be applied to other volcanoes experiencing active ground deformation and seismicity.
\end{abstract}

Key words: Stress field inversion, Campi Flegrei, volcano deformation, volcanic seismicity, joint inversion.

\section{Introduction}

Among the various geophysical phenomena associated with the transportation of magma within

1 Istituto Nazionale di Geofisica e Vulcanologia, sezione di Napoli, via Diocleziano, 328, 80124 Naples, Italy. E-mail: luca.dauria@ingv.it

2 Dipartimento di Scienze e Tecnologie, Università degli Studi del Sannio, via dei Mulini, 59a, 82100 Benevento, Italy. the shallow crust, there is ground deformation, which can be measured using both on-site (e.g., levelling, GPS) and satellite geodetic techniques (e.g., InSAR). In the brittle crust, strains are often associated with the occurrence of volcano-tectonic earthquakes. It follows that the joint analysis of ground deformation and seismicity represents a key method for monitoring active volcanoes (Segall 2013). During the last decades, the exploitation of InSAR and GPS techniques greatly improved the spatial resolution and the continuity of geodetic data sets (DzURISIN 2006). In addition, a large amount of active volcanoes are equipped with seismic networks, able to detect and locate local microseismicity (LEE and STEWART 1981; D’Auria et al. 2011; Tramelli et al. 2013).

Volcanic eruptions are often preceded by an increment in seismicity. Generally, stress changes associated with magma migration and intrusion are believed to cause these earthquakes (UMAKоsнi et al. 2001; Pedersen and Sigmundsson 2004; Segall 2013; Cannavò et al. 2014). For instance, various studies have shown that the migration of seismic swarms can be related to the intrusion of a dyke (TODA et al. 2002; RuBin et al. 1998; BRANDSDOTTIR and EINARSSON 1979; PATANÈ et al. 2003). In general, changes in the volcano-tectonic seismicity pattern can be quantitatively related to variations of the stress field having different origin (Dietrich 1994; Segall 2013). Geodetic or seismic measurements alone, allows putting only limited constraints to models of magma reservoir dynamics (SEGall 2013). In particular, the study of ground deformation alone suffers from a limited resolution in defining the geometry of magmatic bodies, and from an intrinsic ambiguity in the possible solutions to the geodetic inverse problem (DzuRISIN 2006). On the other hand, seismic study 
alone often do not allow a quantitative estimation of the stress field magnitude (ANGELIER 1990).

Conversely, the joint inversion of ground deformation and seismicity data represents a robust and reliable approach to investigate the stress field beneath active volcanoes. For instance, joint analysis of the ground deformation and spatial pattern of $P$ axes has been successfully applied to the modelling of magmatic sources at Mt. Etna (CANnAvò et al. 2014).

Following a novel approach, we propose the quantitative determination of the spatial and temporal variations of the stress field within the Campi Flegrei caldera $(\mathrm{CFc})$ by joint inversion of geodetic and seismological data.

\section{Geological Background}

The Campi Flegrei caldera $(\mathrm{CFc})$ is a collapse structure, partially submerged, and located west of the city of Naples. Its shape is a consequence of two huge collapses due to major eruptive events: the Campanian Ignimbrite eruption (CI 40.6 ky, GEBAUER et al. 2014) and the Neapolitan yellow tuff eruption (NYT 14.9 ky, Deino et al. 2004) (Fig. 1). After the latter event, the area underwent three eruptive periods, between 12 and 3.8 ky (Di Viтo et al. 1999), followed by a long period of quiescence until the last eruption: Monte Nuovo, 1538 CE. The activity of $\mathrm{CFc}$ in the last decades consisted mostly of seismic activity, significant gas emissions and intense ground deformation (Chiodini et al. 2001; D'Auria et al. 2011).

In the last century, there were three major events of uplift in 1950-1952 (about 0.75 m), 1969-1972 $(1.77 \mathrm{~m})$ and during the period 1982-1984 $(1.79 \mathrm{~m})$ (Del Gaudio et al. 2010). A period of subsidence started in 1985 and was interrupted by brief episodes of uplift in the following years (D'AURIA et al. 2011). During the last uplift event (1982-1984), this area was also affected by intense seismicity. The aim of

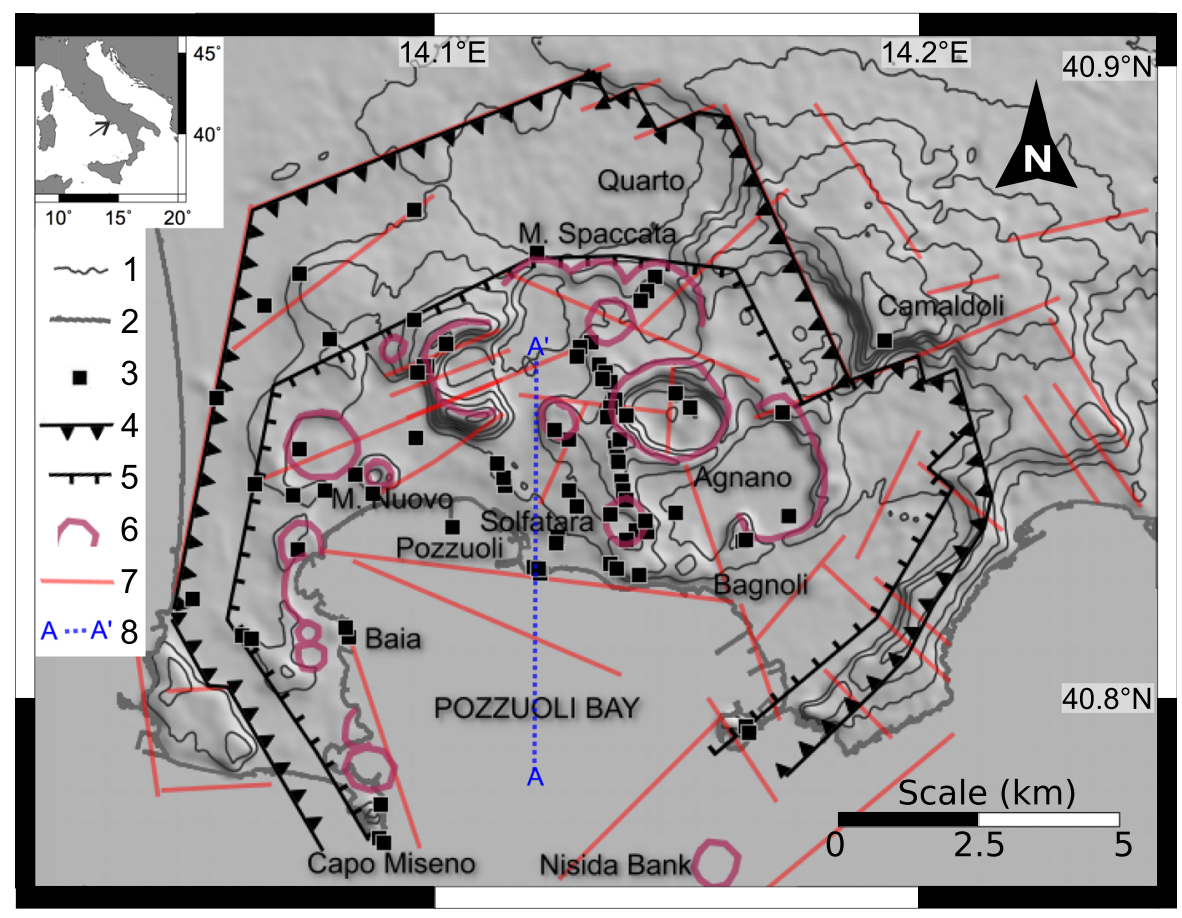

Figure 1

Map of the Campi Flegrei area with an outline of the major tectonic features. Legend (1) $50 \mathrm{~m}$ contour lines, (2) coast line, (3) seismic stations, (4) CI caldera rim, (5) NYT caldera rim, (6) rim of craters younger than $15 \mathrm{ka}$, (7) main fault traces, (8) trace of the N-S section discussed in Fig. 9. Data from Vitale and Isaia (2013) and Orsi et al. (1999) 

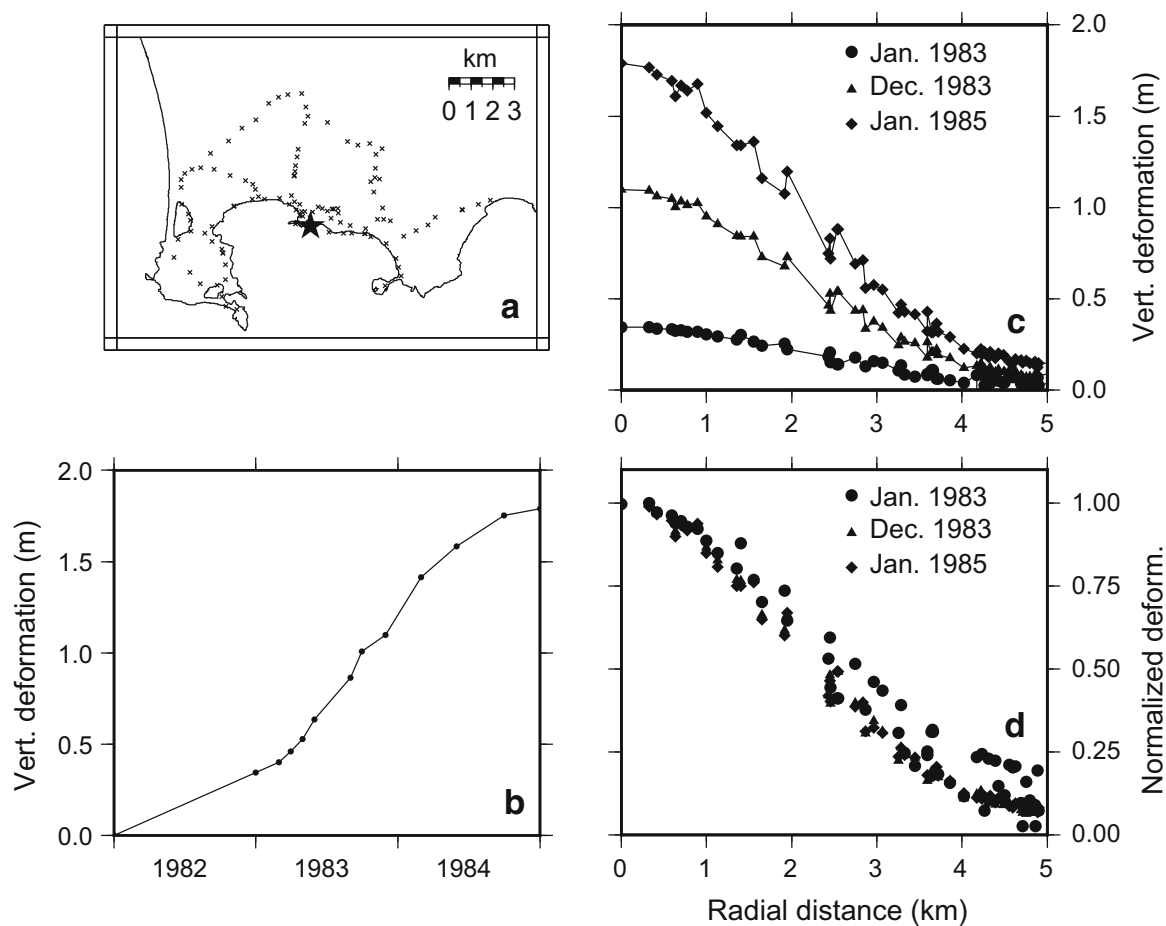

Figure 2

Optical levelling data set. a Map with the full distribution of benchmarks. The star is the position of the benchmark 25 A. b Vertical deformation measured at benchmark $25 \mathrm{~A}$. c Ground deformation pattern. The graph represents the vertical deformation as a function of the radial distance from benchmark $25 \mathrm{~A}$. We show the deformation pattern, referring to the survey of Jan. 1982 at three different times, as indicated by the three different symbols (circle, triangle, diamond). d Same as (c), but with vertical deformations normalised to the value of benchmark $25 \mathrm{~A}$

this work is to determine the spatial and temporal variations of the stress field within the $\mathrm{CFc}$ by joint inversion of geodetic and seismological data related to this last crisis.

\section{Ground Deformation Data Set}

The geodetic data set consists of about 1,100 optical levelling measurements referring to the interval 1982-1985. During this interval 13 surveys were performed, with a number of benchmarks ranging from a minimum of 18 (April 1983) to a maximum of 353 (January 1983). In Fig. 2a, we represent the planimetric distribution of benchmarks used between 1982 and 1985 .

The ground deformation rate showed a marked increase during the first half of 1983, with an average uplift rate at benchmark 25A (black star in Fig. 2a) of about $10 \mathrm{~cm} /$ month. During the second half of 1984, the rate started decreasing, reversing to subsidence since January 1985 (Fig. 2b). The ground deformation shows a roughly radial bell-shaped pattern during the entire period (Fig. 2c). However, a detailed comparison of the pattern during different intervals shows a slight change in the overall shape, in particular in the earlier phases of the crisis (Fig. 2d).

\section{Inversion of the Ground Deformation Data}

The study of ground deformation on active volcanoes is essential to understand the dynamics related to both the magmatic and hydrothermal systems (SEgall 2010). Ground deformation at CFc has been the subject of various studies. In recent years, topics focused on the determination of the roles of the magmatic system and of the hydrothermal system as sources of ground deformation. BATTAGLiA et al. (2006) evidenced that the most likely source for the 
1982-1984 uplift was a penny-shaped crack with a radius of $2.4 \mathrm{~km}$ and at a depth of $2.6 \mathrm{~km}$, probably filled with magmatic fluids. Similar conclusions were also drawn by Woo and KiLbuRn (2010).

On the other hand, the role of the hydrothermal system has been invoked as well, using both analytical (Bonafede 1991) and numerical (CHIODINI et al. 2003) means. In particular, limited uplift episodes occurring at $\mathrm{CFc}$ since 1985 have been ascribed to migration of hydrothermal fluids (GAETA et al. 2003; Battaglia et al. 2006; D’ Auria et al. 2011; СамACHO et al. 2011).

Recently, D'AURIA et al. (2012) evidenced, though a geodetic imaging technique, the migration of hydrothermal fluids as a likely source for the recent episodes of limited ground uplift at $\mathrm{CFc}$ (2000-2007). Those results are in agreement with the results that CАMACHO et al. (2011) obtained with a similar geodetic imaging technique.

In this work, the inversion of the ground deformation data set has been performed using a hybrid non-linear technique. The ground deformation model used for the inversion is:

$$
z_{i}^{k}=s_{k} a_{i},
$$

where the index $k$ refers to the benchmarks and the index $i$ to the optical levelling surveys; the term $s_{k}$ expresses the vertical deformation at the $k$ th benchmark for a given source with normalised amplitude, and $a_{i}$ is the source amplitude at the time of the $i$ th survey. The relationship between the source amplitudes and the data is linear. However, the term $s_{k}$ has a highly non-linear dependence from the source, even for very simple models (e.g., the Mogi point source).

We have addressed this inverse problem by splitting the whole problem into a linear inversion procedure embedded within a non-linear optimization algorithm.

The linear inversion is aimed at determining the value $a_{i}$ given a source model $s_{k}$. To reduce the effect of local biases on the data set, we consider all the possible differences at each benchmark $k$ :

$$
d_{i j}^{k}=z_{i}^{k}-z_{j}^{k} .
$$

Substituting Eq. 2 in 1 and considering a specific source model $s_{k}$, we obtain a system of linear equations in the form: $\boldsymbol{d}=\boldsymbol{G} \boldsymbol{a}$, which we solve by
Table 1

Source models used for the inversion

\begin{tabular}{lllll}
\hline Model & GDOF & DOF & RSS $\left(\mathrm{cm}^{2}\right)$ & AICc \\
\hline MoGi (1958) & 0 & 15 & 2.935 & -6467.680 \\
MCTIGUE (1987) & 1 & 16 & 2.731 & -6544.621 \\
FIALKO et al. (2001) & 1 & 16 & 0.966 & -7684.601 \\
YANG et al. (1988) & 4 & 19 & 0.865 & -7800.115 \\
OKADA (1985) & 4 & 19 & 0.773 & -7923.076 \\
\hline
\end{tabular}

The second column (GDOF) indicates the number of geometric degrees of freedom of the model, while the third is the total number of degrees of freedom (DOF). The fourth (RSS) is the residual sum of squares (Eq. 3), while the fifth (AICc) is the corrected Akaike Information Criterion

computing a pseudo-inverse $\left(\boldsymbol{G}^{+}\right)$using the singular value decomposition: $\boldsymbol{a}^{\text {est }}=\boldsymbol{G}^{+} \boldsymbol{d}$ (Aster et al. 2013). Once source amplitudes have been estimated, we can easily compute the residual sum of squares for the considered source model:

$$
\operatorname{RSS}(s)=\sum_{i, j, k}\left[\left(d_{i j}^{k}\right)^{\mathrm{obs}}-s_{k}\left(a_{i}-a_{j}\right)\right]^{2} .
$$

To determine source model parameters, we have optimised the previous function using a genetic algorithm (SEN and Stoffa 1995).

We have considered five different elementary source models, listed in Table 1. The selection among the candidate models has been performed using the corrected Akaike Information Criterion (AICc) (Burnham and Anderson 2002). The computation of AICc requires the knowledge of the number of degrees of freedom (DOF) associated to the model. In general, we can write: $\mathrm{DOF}=3+\mathrm{GDOF}+(\mathrm{NS}-$ 1 ), where 3 refers to the DOF related to the spatial location of the source, GDOF are the DOF related to the geometry of the source, and NS-1 (with NS being the number of optical levelling surveys) are the DOF associated to the amplitude variations of the source. The term -1 appears because we must constrain the amplitude of the source term at the time of the first survey to be null $\left(a_{1}=0\right)$.

The simplest model is the point source of Mogi (1958), which does not possess any GDOF. The McTigue (1987) model takes into account the source radius and hence has one GDOF. The same holds for the FIALKo et al. (2001) penny-shaped crack model. The YANG et al. (1988) and OKADA (1985) models both 
have four GDOF: the former considers a generally oriented ellipsoid, while the latter considers a simple rectangular crack. In the modelling, values of $2 \mathrm{GPa}$ and 0.25 were assumed for the shear modulus and Poisson's ratio, respectively (D'AuRIA et al. 2012).

The AICc values indicate that the Okada rectangular crack is the best suited from a statistical point of view (Table 1).

In Fig. 3, we summarise the results of the inversion. The red rectangle in Fig. $3 \mathrm{~d}$ is the surface projection of the crack. It has an area of about $16 \mathrm{~km}^{2}$ and its centre is at about at $2.56 \mathrm{~km}$ b.s.l. The crack is dipping slightly $9^{\circ}$ toward the SW. A comparison of observed and synthetic data (Fig. 3a) shows excellent agreement, and the average residuals for each survey show no systematic trends (Fig. 3c). The average residuals for the benchmark (Fig. 3d) show a slight increase in the area E of Pozzuoli. These residuals are probably related to the presence of the Monte Olibano lava dome, whose mechanical properties strongly differ from the surrounding lithologies (Orsi et al. 1996).

Given the Okada source model, it is very easy to derive the corresponding volumetric variation from the crack opening value (see Fig. 3b). The final volumetric variation of the source is about $0.35 \mathrm{~km}^{3}$, which is of the same magnitude as small to mediumsized eruptions at $\mathrm{CFc}$ since $12 \mathrm{ky}\left(0.01-0.1 \mathrm{~km}^{3}\right)$ (Woo and Kilburn 2010).
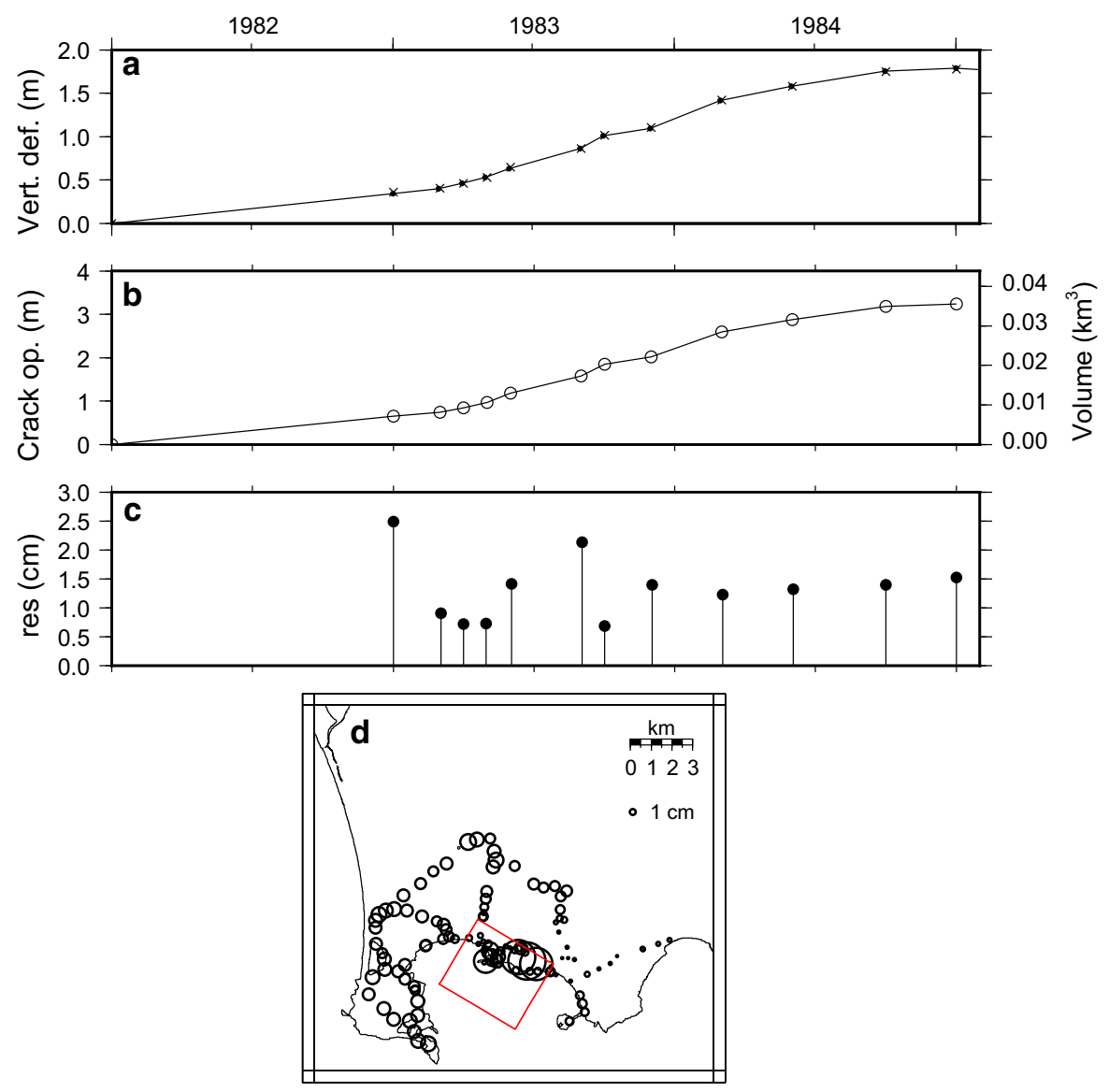

Figure 3

Results of the inversion of the geodetic data set. a Comparison between the observed (crosses) and the synthetic (black dots) vertical ground deformation at the benchmark $25 \mathrm{~A}$. b Opening of the crack and its volumetric variation (scale on the right). c Average residuals for each survey. d Average residuals for each benchmark are indicated with black circles. The scale is reported on the plot. The red rectangle is the surface projection of the ground deformation source 


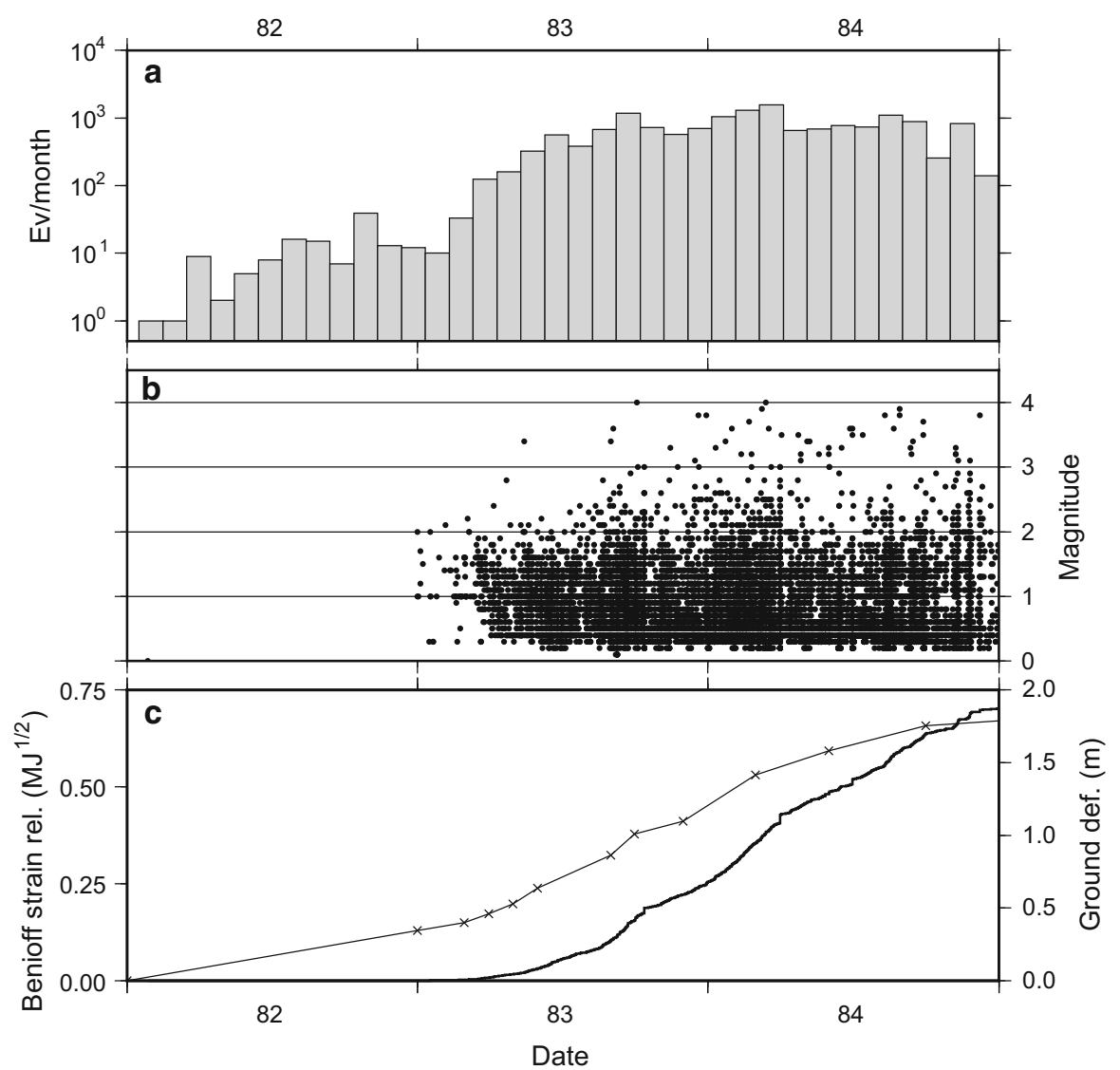

Figure 4

Time series of seismicity and ground deformation. a Monthly number of earthquakes since 1 January 1982. Note that the vertical scale is logarithmic. b Earthquakes magnitudes since 1 January 1983 (magnitudes for events occurring during 1982 are not available). c Comparison between the cumulative Benioff strain release (bold black curve) and the vertical deformation at benchmark 25 A (solid line with crosses)

\section{Seismological Data Set}

The bradyseismic crisis of 1982-1984 was characterised by intense seismicity, with about 16,000 recorded earthquakes and magnitudes ranging from about 0.5 to 4.2 (Fig. 4) (D'Auria et al. 2011). We have analysed 222 events that occurred at $\mathrm{CFc}$ in the interval of 1983-1984. One hundred and ninety-two events have been relocated and their focal mechanisms have been calculated using $P$ wave polarities, using the FPFIT software (REASENBERG and OpPENHEIMER 1985). Among these 192 events, 25 were previously unpublished. Each event has been relocated using a nonlinear probabilistic approach (NonLinLoc software) in a three-dimensional (3D) velocity model (D'AURIA et al. 2008). An additional 30 mechanism data sets have been retrieved from Orsi et al. (1999).
The number of stations operating during the 1982-1984 intervals was highly variable. The analogue single-component network of the Osservatorio Vesuviano (OV) was progressively increased up to 21 stations. From September to November 1983, the Institut de Physique du Globe de Paris, in cooperation with OV, installed a temporary network of 18 digital three-component seismic stations. Moreover, during the interval December 1983-June 1984, the OV network was complemented by ten digital threecomponent stations provided by the University of Wisconsin (Aster and Meyer 1988). In Fig. 1, we report a complete map of the seismic stations operating during the period 1982-1984.

The seismicity during the 1982-1984 bradyseismic crisis increased gradually from the second half of 1982. At the beginning of 1983 , there was a marked 


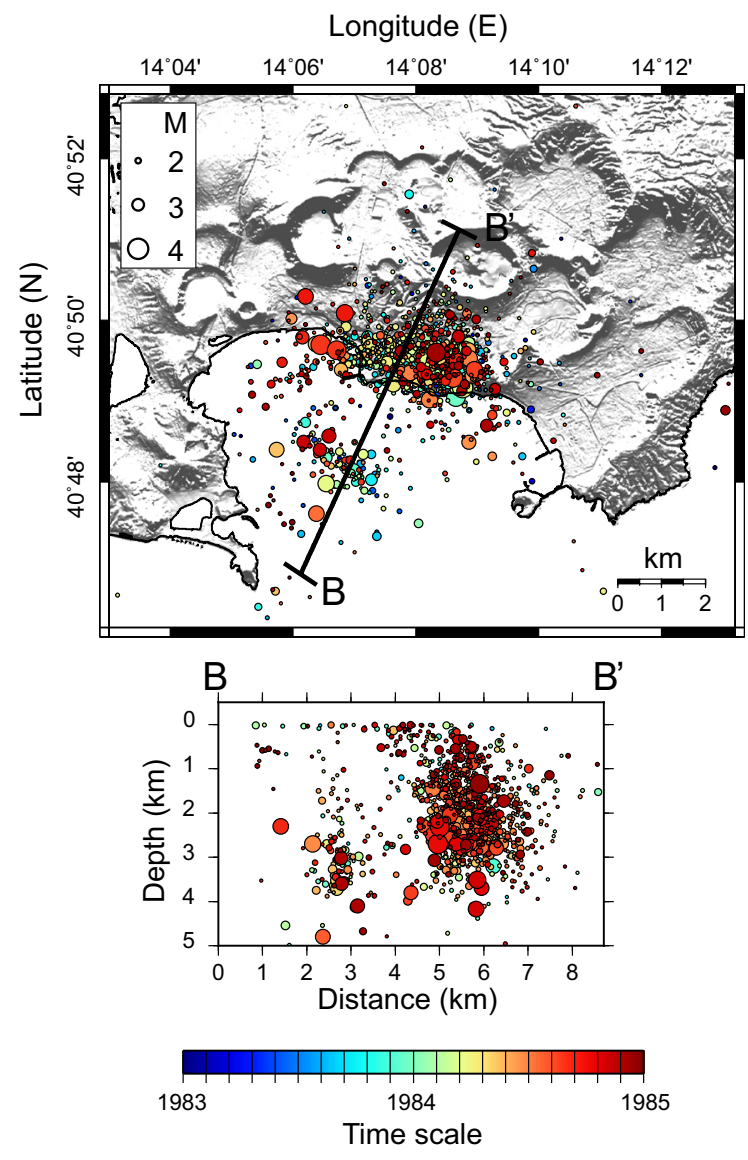

Figure 5

Earthquake hypocentres during 1983-1984. The map shows the distribution of epicentres. In the bottom panel, hypocentres are projected along the $B-B^{\prime}$ section shown on the map. Symbol size is proportional to the magnitude (as shown on the inset on the top left), while the colour scale indicates the time of occurrence (see scale on the bottom)

increase in both the seismicity rate and in the event magnitudes (Fig. 4a, b). The pattern of the seismicity showed an almost stationary rate during 1984 with episodes of intense seismic swarms (e.g., the 1 April 1984 swarm, with more than 400 events occurring in less than $5 \mathrm{~h}$ ). During the entire period, the Benioff strain release pattern roughly followed those of the ground uplift (Fig. 4c), even if the former was slightly delayed (D'Auria et al. 2011).

During the period 1983-1984, epicentres were located mostly in the area between the town of Pozzuoli and Agnano (Fig. 5). Another more limited cluster of events was located within the Pozzuoli Bay (Fig. 5). Hypocentre depth was generally above $3 \mathrm{~km}$ (D’Auria et al. 2011).

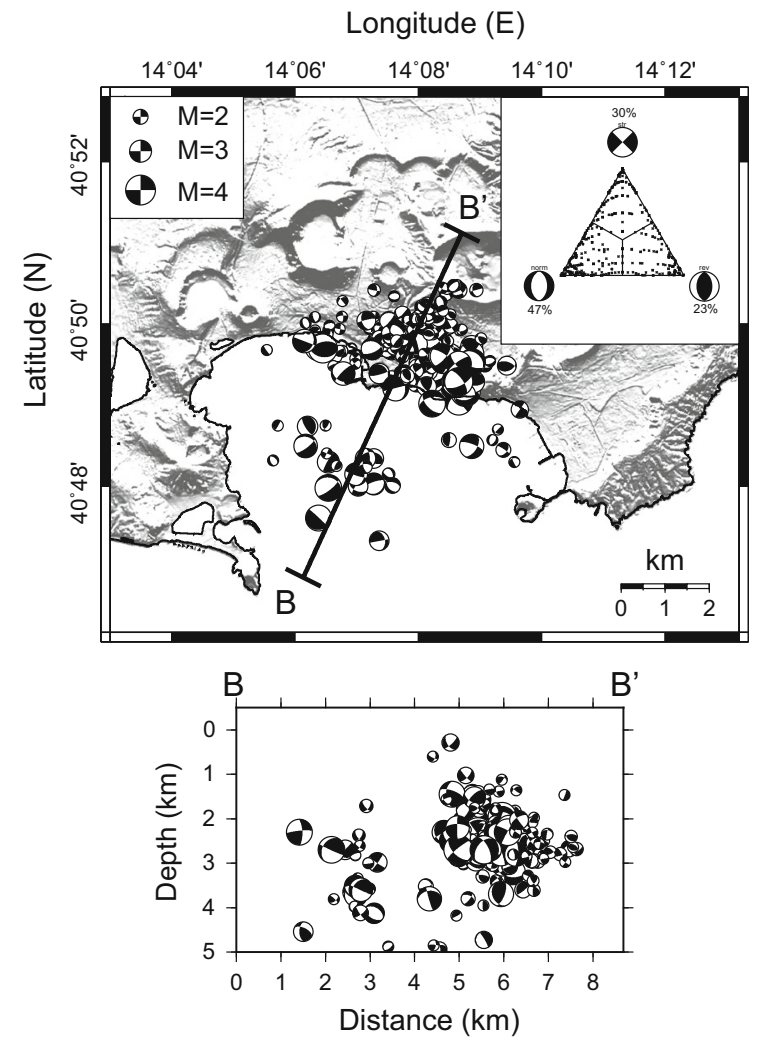

Figure 6

Focal mechanism data set. Focal mechanisms are represented both on a map (top) and along the $\mathrm{B}-\mathrm{B}^{\prime}$ cross-section (bottom). The size of the beachballs is proportional to the magnitude (see inset on the top left). The distribution of mechanism types is shown in the triangular diagram within the inset on the top right following the criterion of FROHLICH (1992)

The 192 re-analysed events have a number of $P$ wave polarities ranging between 6 and 19, with an average value of 8.6. In Fig. 6, we plot the entire focal mechanism data set. Mechanisms show a very heterogeneous distribution among the different typologies. The Frohlich triangular plot shows that normal mechanisms $(47 \%)$ prevail on inverse and strike-slip mechanisms (23 and $30 \%$, respectively) (Fig. 6).

In order to investigate the temporal evolution of the stress pattern in $\mathrm{CFc}$, we split the focal mechanism data set into ten time intervals (A-J, see Table 2). Intervals A to I group data into time windows, while the interval $\mathrm{J}$ represents the entire data set and was processed in order to retrieve the overall stress field acting in the study area (see Sect. 6). The C interval partially overlaps the B one; it contains the event of 4 October 1983, the strongest of the whole crisis $(M=4.2)$ (Fig. 2b). 
Table 2

Time intervals used for the data processing

\begin{tabular}{|c|c|c|c|c|c|c|}
\hline Time intervals & Start & End & Normal (\%) & Thrust (\%) & Trascurrent $(\%)$ & Total \\
\hline A & $1983-01-17 \quad 15: 24$ & $1983-08-22 \quad 07: 31$ & $4(57)$ & $2(28)$ & $1(15)$ & 7 \\
\hline $\mathrm{B}$ & 1983-09-01 23:04 & $1983-10-2923: 30$ & $10(42)$ & $8(33)$ & $6(25)$ & 24 \\
\hline $\mathrm{C}^{\mathrm{a}}$ & 1983-10-04 08:09 & $1983-10-2923: 30$ & $9(52)^{\mathrm{a}}$ & $4(24)^{\mathrm{a}}$ & $4(24)^{\mathrm{a}}$ & $17^{\mathrm{a}}$ \\
\hline $\mathrm{D}$ & $1983-11-0323: 43$ & $1983-12-3023: 19$ & $9(64)$ & $4(29)$ & $1(7)$ & 14 \\
\hline $\mathrm{E}$ & 1984-01-11 05:13 & 1984-03-19 23:52 & $10(38)$ & $5(19)$ & $11(43)$ & 26 \\
\hline $\mathrm{F}$ & 1984-03-20 09:11 & $1984-03-2620: 53$ & $12(37)$ & $9(28)$ & $11(35)$ & 32 \\
\hline G & 1984-04-01 01:04 & 1984-04-01 04:43 & $23(59)$ & $3(8)$ & $13(33)$ & 39 \\
\hline $\mathrm{H}$ & 1984-04-03 16:34 & $1984-04-27$ 15:10 & $25(50)$ & $11(22)$ & $14(28)$ & 50 \\
\hline I & 1984-05-05 14:43 & $1984-12-08$ 22:33 & $11(37)$ & $10(33)$ & $9(30)$ & 30 \\
\hline $\mathrm{J}$ & $1983-01-17 \quad 15: 24$ & $1984-12-08$ 22:33 & $104(47)$ & $52(23)$ & $66(30)$ & 222 \\
\hline
\end{tabular}

${ }^{\text {a }}$ Note that the interval $\mathrm{C}$ is a subset of interval $\mathrm{B}$

\section{Inversion of Focal Mechanisms}

A stress field acting on an intensely fractured rock causes the slip on fault planes oriented along mechanically favourable directions. Simple plotting of focal mechanisms and $P-T$ axes density contouring is usually not enough to constrain the attitude of principal stress axes (McKenZIE 1969).

The application of stress inversion techniques is therefore required to make a reliable reconstruction of the actual stress field responsible for the genesis of the analysed faults. Several methods of stress inversion have been proposed (ANGELIER and Mechler 1977; Michael 1984, 1987; Gephart and Forsyth 1984; Rivera and Cisternas 1990; Yamaji 2000; OtsuBo et al. 2008).

Analytical methods are based on the Wallace-Bott hypothesis, stating that the shear traction applied on a given fault plane causes a slip in the direction and orientation of that shear traction, irrespective of the faults created in an intact rock or along a pre-existing fracture (Wallace 1951; Bott 1959; Angelier and Mechler 1977; YamaJI 2007). Following this hypothesis, the inversion of the stress field is generally done, minimizing a function of the angle between the computed shear stress and the retrieved slip vector on every analysed fault (MichAEL 1984; Angelier 1984, 1990; Hippolyte et al. 2012). Stress field inversion techniques allow the determination of the principal stress axes attitudes, and usually also the Bishop's ratio $\varphi_{\mathrm{B}}=\left(\sigma_{2}-\sigma_{3}\right) /\left(\sigma_{1}-\sigma_{3}\right)$ (Bishop 1966), which is a relationship between principal stress eigenvalues that is useful to describe the shape of the stress ellipsoid.

Another class of stress inversion methods is based on a graphic approach. The simplest graphic approach to the stress inversion of a focal mechanism data set is the Right Dihedra Method (RDM; AngeLIER and MECHLER 1977). The RDM allows the determination of a range of possible attitudes for the principal stress axes through the use of the stereographic projection technique (RAMSAY and LISLE 2000; HiPPOLYTE et al. 2012). RDM do not require an a priori selection of the real fault plane to respect to the auxiliary one.

Gaudiosi and IANnACCONE (1984) performed a preliminary analysis of focal mechanisms at CFc. They processed 15 mechanisms related to the interval April-December 1983 without using a stress inversion procedure, and maintained that no regional stress components seem to dominate the stress field in Campi Flegrei area. They related the observed seismicity only to magmatic processes acting in the Pozzuoli area. ZupPeTta and SAVA (1991), applying an analytical stress inversion procedure to 49 focal mechanisms, retrieved for the $\mathrm{CFc}$ area an overall extensional stress field dominated by a sub-vertical $\sigma_{1}$ and a NNE-SSW trending sub-horizontal $\sigma_{3}$.

In this work, we performed the stress inversion procedure, applying a recent formulation of the RDM proposed by D'Auria et al. (2014). This implementation consists of an analysis of normalised moment tensors for the studied events. Following this approach, RDM can be expressed as: 


$$
\operatorname{RDM}(\theta, \varphi)=\frac{1}{N} \sum_{k} \operatorname{sgn}\left(\widehat{x}_{k}(\theta, \varphi) M_{k} \widehat{x}_{k}^{T}(\theta, \varphi)\right),
$$

where $\theta$ and $\phi$ are the polar coordinates on the focal sphere, $M_{k}$ is the normalised moment tensor for the event $k, \widehat{x}_{k}(\theta, \phi)$ is the position vector of the point on the focal sphere, and $N$ is the number of events. The function $R D M(\theta, \phi)$ varies between -1 and 1 , with negative values corresponding to high probabilities of representing the actual $\sigma_{3}$ (blue shades in Fig. 6) and positive values representing the actual $\sigma_{1}$ (red shades in Fig. 6).

In Fig. 7, we show the results of the RDM stress inversion performed on subsets of Table 2. In particular, Fig. $7 \mathrm{j}$ shows the result of the RDM applied to the entire data set. It shows a well-defined $\sigma_{1}$ attitude that appears sub-vertical, corresponding to a less defined $\sigma_{3}$, roughly sub-horizontal and trending NNE-SSW. RDM plot of individual subsets (Fig. 7a-i) generally show an agreement with the global pattern (Fig. $7 \mathrm{j}$ ), indicating a substantial stability in the stress pattern during the entire considered period. The comparison of results for each interval shows a certain degree of heterogeneity. To further constrain these results, we have applied another technique to the same dataset: the Multiple Inverse Method (MIM; YAMAJI 2000). Frequently, focal mechanism data sets are quite heterogeneous regarding stress fields responsible for their own genesis. Many methods aimed at the processing of heterogeneous data have been proposed (Angelier and Manoussis 1980; Angelier 1984; Yamaji 2000; Оtsubo et al. 2008). Operating without a priori information, the MIM is able to separate stresses within data sets related to heterogeneous stress fields, but in which it is possible to find domains where the state of stress is uniform (YAmAJi 2000; Otsubo et al. 2008). MIM operates a resampling of the data set, through the construction of $k$ element subsets. Every subset is inverted using a classical approach for stress tensor inversion (ANGelier 1984; YAmaJi 2000). Results are plotted as "tadpole" symbols on the unit sphere, and significant results are identified by clusters of tadpoles (Отsuво et al. 2006). MIM is able to manage focal mechanism
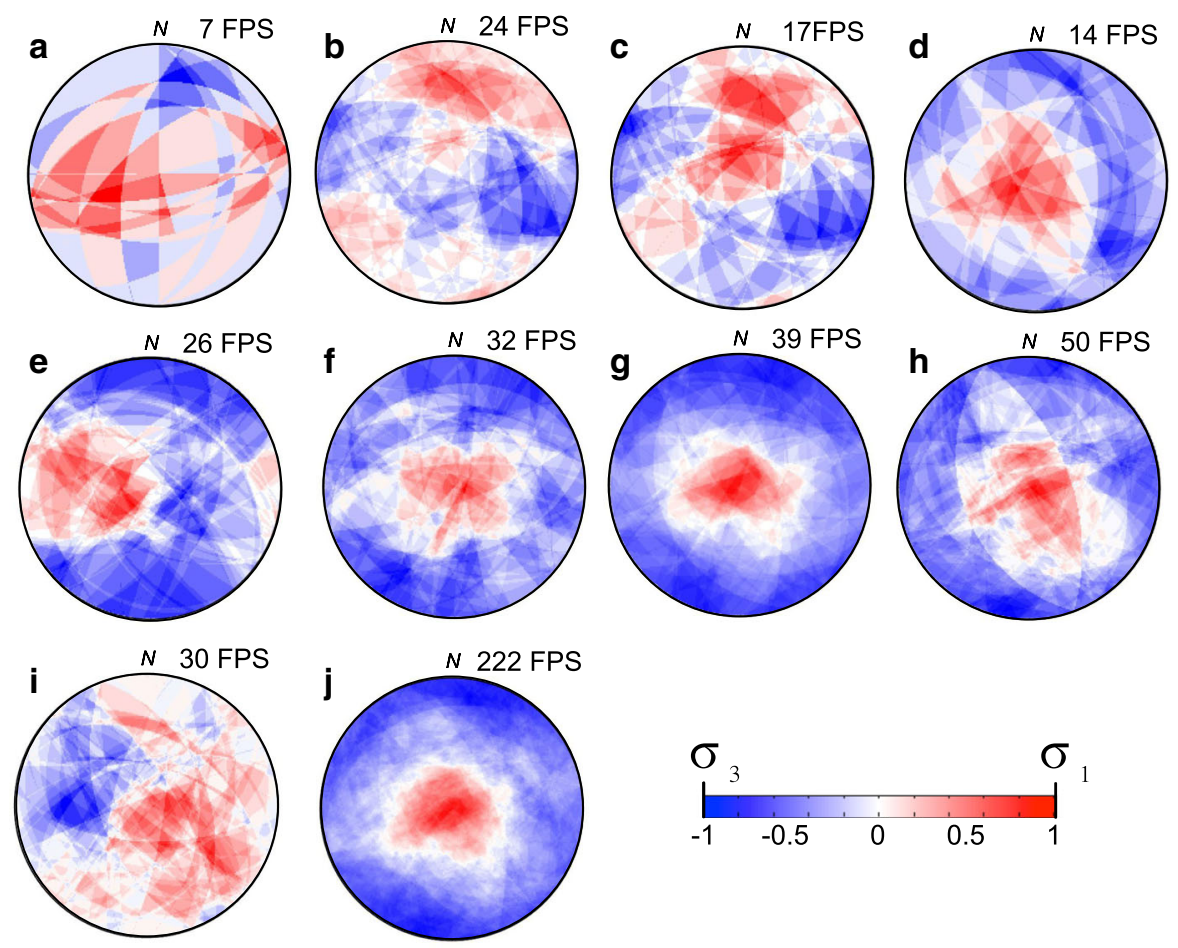

Figure 7

Results of the Right Dihedra Method (RDM). As indicated by the colour scale, blue shades indicate a high probability of containing $\sigma_{3}$, while red shades indicate high probability of containing $\sigma_{1}$ 
data, without requiring the discrimination of a real fault plane with respect to auxiliary plane (OTSUBO et al. 2006; YамалI and Отsubo 2011).

In Fig. 8, we show the results of the MIM over the intervals of Table 2. An overall comparison of Figs. 7 and 8 shows that the results of RDM and MIM are in quite good agreement.

In Fig. $8 \mathrm{j}$, we show the result obtained from the inversion of the entire focal mechanism data set (interval $\mathbf{J}$ in Table 2). It shows a strong clustering of tadpoles representing sub-vertical $\sigma_{1}$ attitudes (Fig. 8j, left plot), corresponding to very low clustered subhorizontal $\sigma_{3}$ tadpoles (Fig. 8j, right plot) located all around the primitive circle, with a slight prevalence of NNE-SSW clusters. The prevalence of green-to-blue clusters of tadpoles allows the evaluation of the prevailing Bishop's ratio values $0<\Phi_{\mathrm{B}}<0.5$. These results are in accordance with the RDM result (Fig. 7j), and are useful to highlight the strong heterogeneity of the analysed data set.

The A subset consists of only seven focal mechanisms. The RDM shows that a well-defined subhorizontal $\sigma_{3}$, plunging toward NNE, corresponds to a poorly defined $\sigma_{1}$ attitude (low plunge toward ENE, medium plunge toward WSW) (Fig. 7a). The MIM results appear quite heterogeneous with a low clustering for both $\sigma_{1}$ and $\sigma_{3}$ axes (Fig. 8a). The RDM for the B subset (Fig. 7b) shows that both $\sigma_{1}$ and $\sigma_{3}$ axes are defined quite well, with a $\sigma_{1}$ plunging toward NNE and corresponding to a sub-horizontal $\sigma_{3}$ trending WNW-ESE. The MIM inversion of the $\mathrm{B}$ subset shows that the data set is highly heterogeneous, possibly deriving from a superposition of different stress fields. The prevailing one consists of a $\sigma_{1}$ medium to high plunging toward E, corresponding to a sub-horizontal $\mathrm{N}-\mathrm{S}$ trending $\sigma_{3}$; the corresponding $\Phi_{\mathrm{B}}$ (yellow to light green tadpoles) is about 0.5 .

The RDM of the $\mathrm{C}$ subset (Fig. 7c) shows that the retrieved $\sigma_{1}$ and $\sigma_{3}$ axes attitudes is very similar to $\mathrm{B}$, with $\sigma_{1}$ areas extended toward high plunge values. The $\sigma_{1}$ and $\sigma_{3}$ axes attitudes retrieved using MIM (Fig. 8c) are very similar to those of $B$; the data set is dominated by a medium-high plunging $\sigma_{1}$ dipping toward $\mathrm{E}$, corresponding to a sub-horizontal $\mathrm{N}-\mathrm{S}$ trending $\sigma_{3}$, and the corresponding $\varphi_{\mathrm{B}}$ tends to be higher than $\mathrm{B}$ (light green tadpoles), likely greater than 0.5 .
The RDM solution for the D subset (Fig. 7d) shows a well-defined, high-plunge $\sigma_{1}$ corresponding to a poorly constrained $\sigma_{3}$ axis associated with areas extended along a great circle dipping toward ENE. The MIM applied to the same subset shows very similar results (Fig. 8d). For the E subset, the RDM result shows quite good definition for the $\sigma_{1}$ axis lowmedium plunging toward $\mathrm{WNW}$, corresponding to a less defined $\sigma_{3}$, with blue areas extending along an $\mathrm{E}$ dipping great circle, with a poor prevalence of subhorizontal N-S trending values (Fig. 7e). Also, in this case, the agreement between RDM and MIM is good (Fig. 8e). RDM inversions for F, G and $\mathrm{H}$ subsets give similar results, compatible with a well-defined, sub-vertical $\sigma_{1}$, corresponding to a less defined low plunge $\sigma_{3}$ trending NNE-SSW (Fig. 7f-h). The MIM results for the same intervals show a higher variability of the $\sigma_{1}$, with a prevailing clustering comparable with RDM results (Fig. 8f-h). The retrieved RDM results for the I subset show a welldefined $\sigma_{3}$ plunging toward the west, corresponding to a poorly defined $\sigma_{1}$ with areas located along a wide E dipping great circle (Fig. 7i). On the other hand, the MIM results show a more clear distribution of clusters, with a prevalence of medium to high E plunging $\sigma_{1}$ corresponding to a sub-horizontal NNE-SSW $\sigma_{3}$. The prevailing clusters are characterised by high values of $\Phi_{\mathrm{B}}$.

\section{Joint Inversion}

The retrieved ground deformation source (Sect. 4) allows computing of the local stress field due to the inflation of the crack. In our case, this can be achieved by using an analytical formulation (OKADA 1992), but for general source models, numerical techniques (e.g., finite elements) could be used as well.

A more general model for the stress field acting in a volcanic area during unrest episodes is:

$$
\sigma(x, t)=\sigma_{0}(x)+\sigma_{\mathrm{M}}(x) a(t),
$$

where $\sigma_{0}(x)$ is the background stress field acting on the volcano before the unrest episode, $a(t)$ is a timevarying function describing the temporal pattern of the ground deformation source (i.e., in our case, it is 

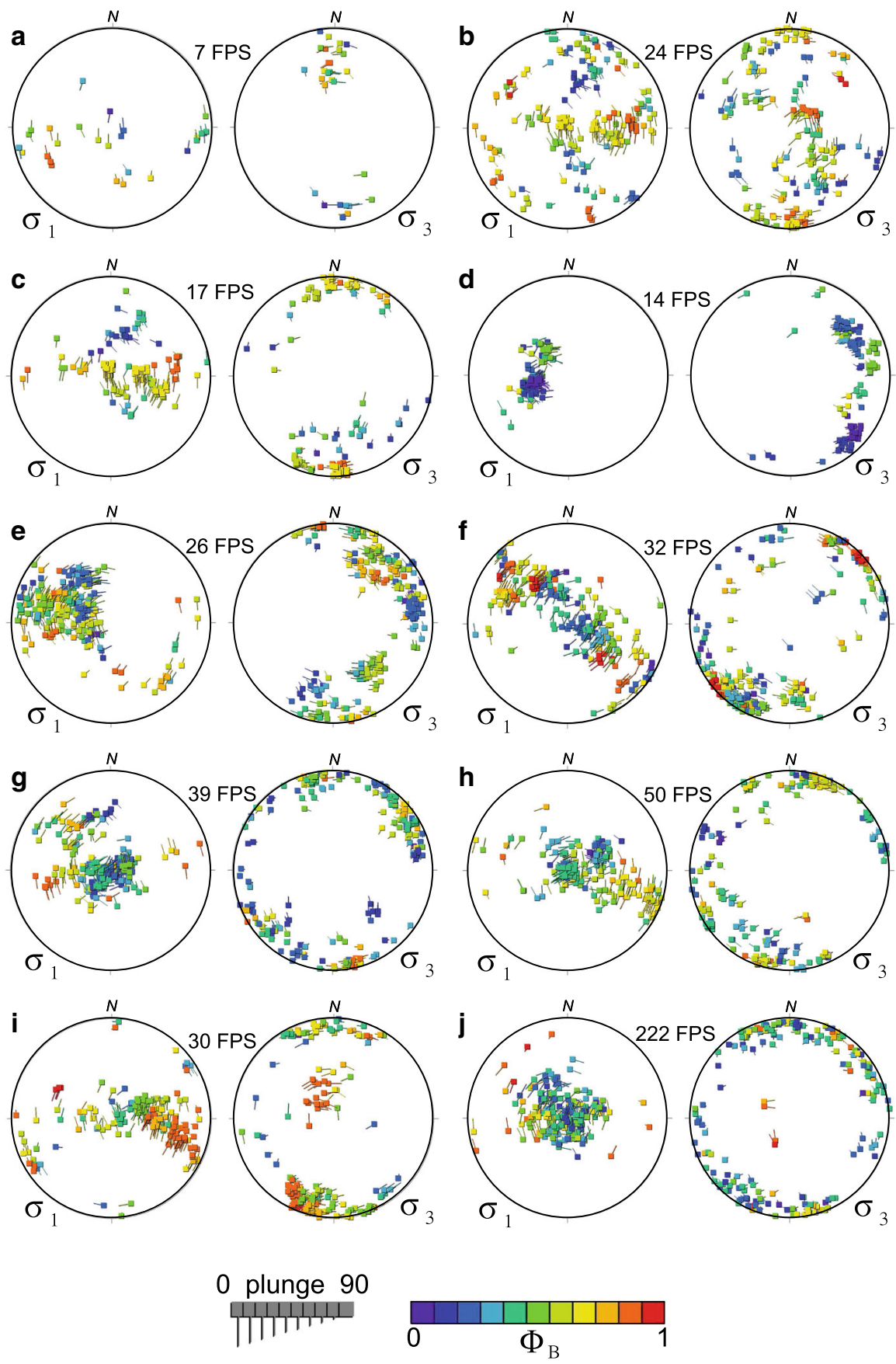

Figure 8

Results of the Multiple Inverse Method (MIM) processing of the focal mechanisms for each interval. Results are represented as clusters of tadpoles for both $\sigma_{1}$ and $\sigma_{3}$ axes (equal area, lower hemisphere). The colour of tadpoles is representative of their $\phi_{\mathrm{B}}$ value (see scales on the bottom). Every depicted $\sigma_{1}$ tadpole (plot on the left) has a tail that allows retrieval of the corresponding $\sigma_{3}$ in the plot on the right. The $\sigma_{1}$ tail points toward the trend of the corresponding $\sigma_{3}$, and the length of each tail is inversely proportional to the $\sigma_{3}$ plunge (see scale below); the same applies to $\sigma_{3}$ for the plot on the right (Yамалг and Oтsuвo 2011) 
just the crack aperture) and $\sigma_{\mathrm{M}}(x)$ is the perturbation of the stress field in the volcano generated by a reference source (i.e., $a=1$ ). In Eq. 5, we assume that the stress field in the volcano is modulated by a scalar function $a(t)$ according to a simple linear relationship. In detail, the background stress $\sigma_{0}$ can be expressed as:

$$
\sigma_{0}=\sigma_{\mathrm{R}}+\sigma_{\mathrm{L}}(x)+\sigma_{\mathrm{M}}(x) a_{0},
$$

where $\sigma_{\mathrm{R}}$ is a stationary background regional field, $\sigma_{\mathrm{L}}(x)$ is the lithostatic load and $a_{0}$ is a constant that takes into account residual stresses deriving from previous unrest episodes arising from a similar ground deformation source. In the following, we assume that $\sigma_{\mathrm{L}}(x)$ is nearly isotropic and not contributing to the deviatoric stress field pattern. Under this assumption, we can rewrite Eq. 5 as:

$$
\sigma(x, t)=\sigma_{\mathrm{M}}(t)\left[a(t)+a_{0}\right]+\sigma_{\mathrm{R}} .
$$

In the previous expression, the function $a(t)$ is already known from the inversion of the ground deformation data (Sect. 4), and the spatial pattern $\sigma_{\mathrm{M}}(x)$ can be computed easily for a given source model. The unknown regional field $\sigma_{\mathrm{R}}$ and the constant $a_{0}$ need to be determined from an independent data set. The focal mechanism data could be successfully used to accomplish this task.

As already mentioned in Sect. 6, the inversion of focal mechanisms provides an estimate of the stress tensor. Among the various inversion techniques, we consider the approach of ANGELIER (1990), which consists of a minimisation of the difference between the slip vector $s$ on each fault and the direction of the maximum shear stress $\tau$ acting on it. In practice, the technique consists of searching the global minimum of the function $E=\sum_{k}\left|\delta_{k}\right|^{2}$, where $\delta_{k}=$ $s_{k}-\left[\xi_{k}-\left(\xi_{k} \times n_{k}\right) n_{k}\right]$. In the previous expression, $s_{k}$ represents the slip associated with the $k$ th focal mechanism of the data set, $n_{k}$ is the corresponding normal vector to the fault plane, and $\xi_{k}$ is the stress vector acting on the fault surface (i.e., $\xi_{k}=\sigma n_{k}$ ). We used a non-linear optimization technique over the model parameters $m=\left[\alpha, \theta, l, \psi, \phi_{B}, a_{0}\right]$, with $\alpha$ as the magnitude of $\sigma_{1}, \theta$ the trend of $\sigma_{1}, l$ its plunge, $\psi$ the rotation of $\sigma_{3}$ around the $\sigma_{1}$ axis, $\Phi_{\mathrm{B}}$ as the Bishop's ratio, and $a_{0}$ is specified in Eq. 6. The first five parameters determine the regional stress tensor $\sigma_{R}$
Table 3

Results of the joint inversion

\begin{tabular}{lc}
\hline Parameter & Value \\
\hline$\sigma_{1}$ Magnitude & $0.39 \pm 0.20 \mathrm{MPa}$ \\
$\sigma_{1}$ Trend & $266^{\circ} \pm 8.2^{\circ}$ \\
$\sigma_{1}$ Plunge & $10^{\circ} \pm 5.9^{\circ}$ \\
$\sigma_{3}$ Trend & $0^{\circ} \pm 11.5^{\circ}$ \\
$\sigma_{3}$ Plunge & $17^{\circ} \pm 5.3^{\circ}$ \\
$\Phi_{\mathrm{B}}$ & $0.42 \pm 0.25$ \\
$\mathrm{a}_{0}$ & $0.0003 \pm 0.0250 \mathrm{~m}$ \\
\hline
\end{tabular}

specified in Eq. 7. The non-linear optimization has been performed using a two-step algorithm, with the first step being a Monte Carlo search and the second an optimization using the NELDER and MEAd (1965) simplex algorithm. The results of the optimization are shown in Table 3, expressed in terms of attitudes of $\sigma_{1}$ and $\sigma_{3}$. To estimate the uncertainty of each parameter, we used a bootstrap approach (EFRON 1979; MicheAL 1987).

The results indicate that, together with the stress field related to volcanic processes, a weak background regional field acts on the area. The orientation of field is compatible with those retrieved by D'AURIA et al. (2014) for the deeper seismogenic volume at the nearby Mt. Vesuvius volcano. The reduction in the misfit function resulting from considering the regional field is about $4 \%$. Nevertheless, the comparison between the modelled stress field and the results shown in Figs. 7 and 8 evidence that the contribution of $\sigma_{\mathrm{R}}$ is not negligible. It is worth noting that the value of the retrieved $a_{0}$ is close to zero, indicating that the effect of previous uplift events on the stress

Figure 9

Results of the joint inversion. The left column shows the $\sigma_{1}$ and $\sigma_{3}$ axes (respectively in red and blue) projected along a $\mathrm{S}-\mathrm{N}$ cross section (A-A' in Fig. 1) The projection of the source crack is outlined in green. Black contours indicate the values of the $\sigma_{1}$ magnitude (in $\mathrm{MPa}$ ). The central and the right columns respectively show the stereographic projections of $\sigma_{1}$ and $\sigma_{3}$ axes within the seismogenic volume (see text for details). Triangles represent the regional principal stress axes (see Sect. 7). (a), (b) and (c) refer to the interval 1/1/1982-1/1/1983. (d), (e) and (f) refer to the interval 1/1/1982-1/7/1983. (g), (h) and (i) refer to the interval 1/1/ 1982-1/1/1984. (j), (k) and (l) refer to the interval 1/1/1982-1/1/ 1985. (m), (n) and (o) represent the stress pattern of the volcanic source alone 

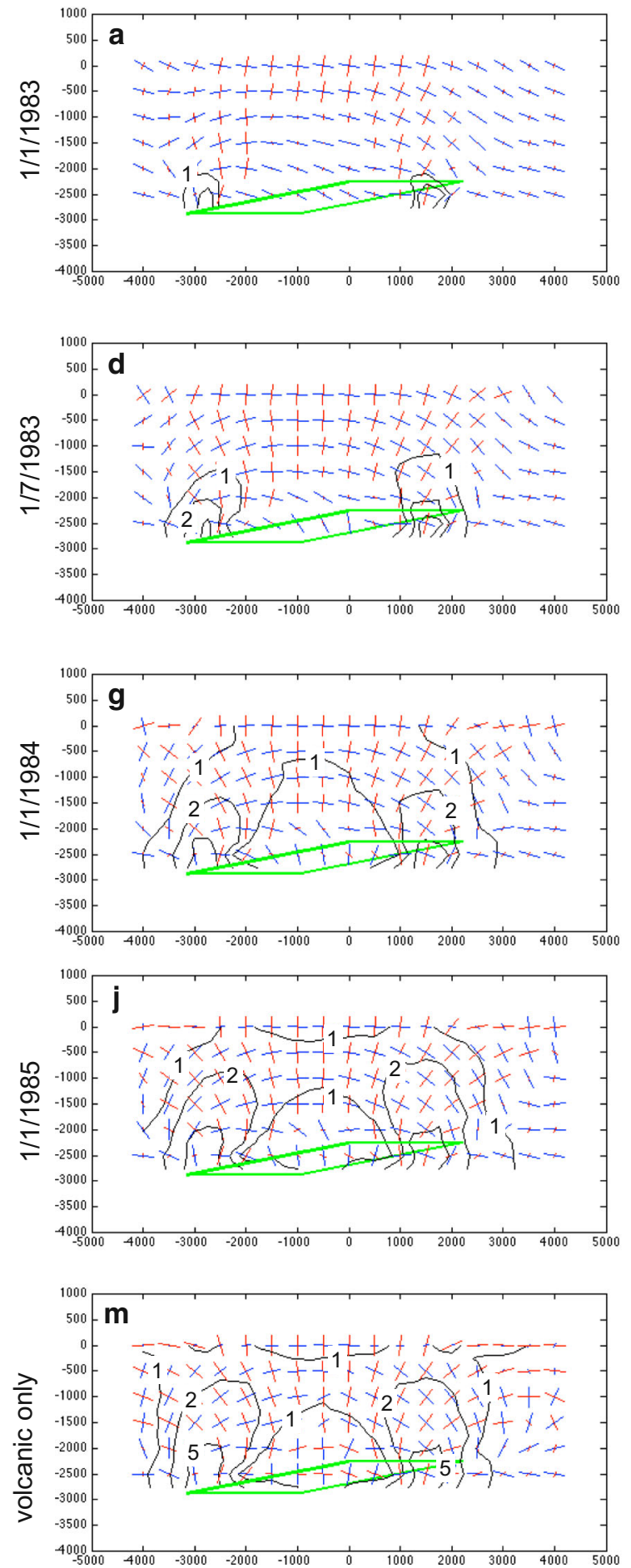

N
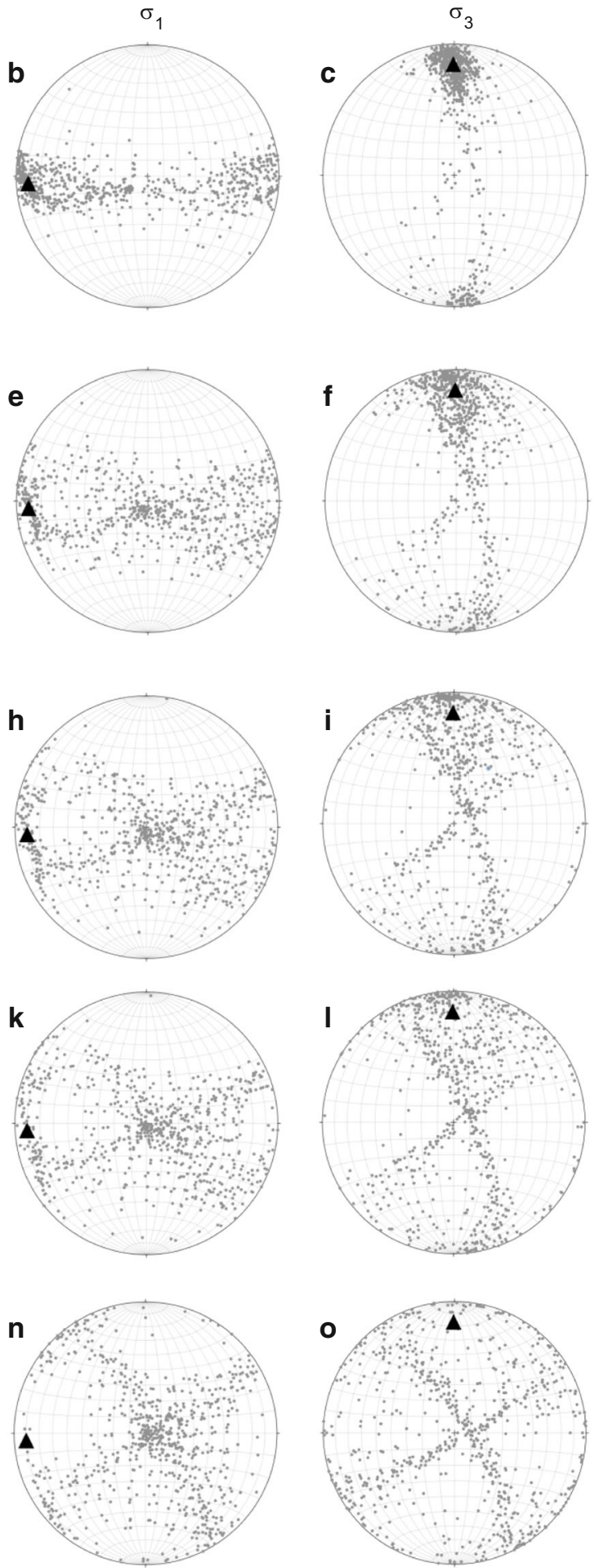
field at $\mathrm{CFc}$ had already almost completely vanished in 1982.

In Fig. 9, we represent the temporal evolution of the modelled stress field beneath CFc. We have computed the theoretical stress field on a regular grid of $8 \times 8 \times 4 \mathrm{~km}$, centred on benchmark $25 \mathrm{~A}$ and with regular spacing of $250 \mathrm{~m}$. In the first columns of Fig. 9, we represent the orientation of $\sigma_{1}$ and $\sigma_{3}$ along a N-S cross-section (Fig. 1), also contouring the magnitude of $\sigma_{1}$. In the second and third columns, the principal stress axes attitudes are plotted in stereographic projections. In the first period (Jan. 1983), the regional field is still dominant (Fig. 9a-c). However, during the first half of 1983, the subvertical dip of $\sigma_{1}$ becomes evident. This feature persists during the rest of the period. Moreover, the sub-horizontal N-S trending $\sigma_{3}$ persists until 1985. It is important to note that the stress field generated by the volcanic source alone (last row in Fig. 9) is not able to reproduce the distribution of $\sigma_{3}$ retrieved from the inversion of the focal mechanism data set (Figs. 7, 8).

\section{Discussion and Conclusions}

The inversion of the focal mechanism data set has been performed using two different approaches: the RDM and the MIM, with results summarised in Figs. 7 and 8. The overall results highlight that the stress fields acting in the $\mathrm{CFc}$ in the interval 1982-1984 are dominated by a well-defined, subvertical $\sigma_{1}$ corresponding to a less defined sub-horizontal $\sigma_{3}$ with a prevalence of NNE-SSW trends (Figs. 7j, 8j). In particular, the MIM is able to correctly identify different clusters within each subset. A comparison of results of RDM and MIM shows good agreement (Figs. 7, 8), and hence supports the reliability of the results. Moreover, we notice that there is good agreement between our results and those of ZupPeTta and SAva (1991).

The non-linear inversion of the optical levelling data set has shown that the best-fit ground deformation source for the 1982-1984 interval is a simple sub-horizontal crack. This source is able to model most of the observed ground deformation (Fig. 3). However, the stress field related to this source alone consists of a nearly subvertical $\sigma_{1}$ and a quite scattered $\sigma_{3}$ (Fig. 9m, n, o).
In Sect. 7, we illustrated a novel approach for the joint inversion of the ground deformation and focal mechanism data sets. The key results are that the retrieved sub-vertical $\sigma_{1}$ is mainly related to the effect of the ground deformation source; however, considering the pattern of $\sigma_{3}$ obtained by both RDM and MIM approaches, an additional background field is required. The joint inversion used in this work allows the determination of the general features of this field, shich consist of a weak extensional $\mathrm{N}-\mathrm{S}$ regional stress field driving the orientation of the $\sigma_{3}$ axes (Fig. 9). The orientation of this field is compatible with that retrieved at the nearby Mt. Vesuvius volcano (D'Auria et al. 2014). The regional field is dominant only in the first phases of the 1982-1984 crisis (Fig. 9a-c). During the first half of 1983, the volcanic deformation source becomes prevalent over the regional background field (Fig. 9d-f). This behaviour matches with the stress pattern inferred from focal mechanisms (Figs. 7, 8), which shows only slight variations during intervals A-C (JanuaryOctober 1983). Since November 1983, the stress field pattern became quite stable with a sub-vertical $\sigma_{1}$ and a sub-horizontal $\sigma_{3}$ (intervals D-I in Table 1).

In conclusion, our results indicate that spatial and temporal variations of the stress field can be related to volcano dynamics and could be linked to the intrusion of fluids (possibly of magmatic nature) within a planar structure. Recently, MACEDONIO et al. (2014) evidenced how the intrusion of sills at a shallow depth can be a realistic model to explain volcanic unrest in calderas.

Our results also have implications for a better comprehension of seismogenic processes at CFc.

In the first column of Fig. 9, we plot the magnitude of $\sigma_{1}$ at different time intervals. It is evident how it is concentrated along the edges of the rectangular crack. This effect is well known for this type of source (OKAdA 1992). Comparing Fig. 9 with the hypocentre locations in Fig. 5, we notice that earthquakes are grouped in two main clusters, whose positions roughly match the northern and southern edges of the ground deformation source (Fig. 3d). TROISE et al. (2003) emphasised how Coulomb stress changes in relation to magmatic processesare important in determining the location of earthquake hypocentres at CFc. However, detailed study of the 
relationship between ground deformation and seismogenesis at CFc must take into account the effect of hydrothermal fluids that play a fundamental role in volcanic areas (BIANCo et al. 2004; D'Auria et al. 2011).

The technique proposed in this work could be applied to other volcanic contexts. We emphasise that the joint inversion of ground deformation and focal mechanism is more efficient than the mere comparison of the results obtained by the separate inversion. Segall et al. (2013) proposed a similar approach, which is based on the computation of Coulomb stress changes. They model the observed migration of earthquake hypocentres during dike propagation in volcanoes.

Finally, we emphasise that the $\mathrm{CFc}$ area is densely populated and hence subject to a high volcanic risk (ORSI et al. 2004). The last bradyseismic crisis of 1982-1984 led to the temporary evacuation of most of the town of Pozzuoli because of the ongoing seismic crisis (BARBERI et al. 1984). For this reason, a better understanding of the relationship between earthquakes and ground deformation at $\mathrm{CFc}$ is important not only from a scientific point of view, but also to support decision makers during the management of possible future volcanic emergencies in this area.

\section{Acknowledgments}

This work has been realised in the framework of an MED-SUV project. MED-SUV has received funding from the European Union's Seventh Programme for research, technological development and demonstration under grant agreement No. 308665.

\section{REFERENCES}

Angelier, J. (1984), Tectonic analysis of fault slip data sets, J. Geophys. Res., 89, 5835-5848.

Angelier, J. (1990), Inversion of Field Data in Fault Tectonics to Obtain the Regional Stress. 3. A New Rapid Direct Inversion Method by Analytical Means, Geophys. J. Int., 103, 363-376.

Angelier, J. T., and Mechler, P. (1977), Sur une methode graphique de recherche des contraintes principales egalement utilisables en tectonique et en seismologie: la methode des diedres droits. Bulletin de la Société géologique de France (7), t.XIX, nº, 1309-1318.
Angelier, J., and Manoussis, S. (1980), Classification automatique et distinction des phases superposées en tectonique de failles. CR Acad. Sci. Paris, 290, 651-654.

Aster, R. C., and Meyer, R. P. (1988), Three-dimensional velocity structure and hypocenter distribution in the Campi Flegrei caldera, Italy. Tectonophysics, 149(3), 195-218.

Aster, R. C., Borchers, B., and Thurber, C. H. (2013), Parameter estimation and inverse problems (Academic Press).

BrandSdotTir, B., and EINARsson, P. (1979). Seismic activity associated with the September 1977 deflation of the Krafla central volcano in northern Iceland, J. Volc. Geotherm. Res., 6, 197-212.

Barberi, F., Corrado, G., Innocenti, F. and Luongo, G. (1984), Phlegraean Fields 1982-1984: brief chronicle of a volcano emergency in a densely populated area. Bull. Volcanol., 47(2): 175-185.

Battaglia, M., Troise, C., Obrizzo, F., Pingue, F., and De Natale, G. (2006), Evidence for fluid migration as the source of deformation at Campi Flegrei caldera (Italy). Geophysical Research Letters, 33(1), L01307.

Bianco, F., Del Pezzo, E., Saccorotti, G., and Ventura, G. (2004), The role of hydrothermal fluids in triggering the July-August 2000 seismic swarm at Campi Flegrei, Italy: evidence from seismological and mesostructural data. Journal of Volcanology and Geothermal Research, 133(1), 229-246.

BISHOP (1966), The strength of solids as engineering materials, Geotechnique, 16, pp. 91-130.

Bonafede, M. (1991), Hot fluid migration, an efficient source of ground deformation: Application to the 1982-1985 crisis at Campi Flegrei-Italy, J. Volcanol. Geotherm. Res., 48, 187-198.

Bотт, M. H. P. (1959), The mechanics of oblique slip faulting, Geol. Mag., 96, 109-117.

Burnham, K. P., and Anderson, D. R. (2002), Model selection and multimodel inference: a practical information-theoretic approach. Springer.

Camacho, A. G., P. J. González, J. Fernández, and G. Berrino (2011), Simultaneous inversion of surface deformation and gravity changes by means of extended bodies with a free geometry: Application to deforming calderas, J. Geophys. Res., 116, B10401, doi:10.1029/2010JB008165.

Cannavò, F., Scandura, D., Palano, M. and Musumeci C. (2014), A Joint Inversion of Ground Deformation and Focal Mechanisms Data for Magmatic Source Modelling. Pure and Applied Geophysics, doi:10.1007/s00024-013-0771-x.

Chiodini, G., Frondini, F., Cardellini, C., Granieri, D., Marini, L., and Ventura, G. (2001), $\mathrm{CO}_{2}$ degassing and energy release at Solfatara volcano, Campi Flegrei, Italy. Journal of Geophysical Research: Solid Earth (1978-2012), 106(B8), 16213-16221.

Chiodini, G., M. Todesco, S. Caliro, C. Del Gaudio, G. MacedoNIO, and M. Russo (2003), Magma degassing as a trigger of bradyseismic events: The case of Phlegrean Fields (Italy), Geophys. Res. Lett., 30(8), 1434, doi:10.1029/2002GL016790.

D’Auria, L., Giudicepietro, F., Aquino, I., Borriello, G., Del Gaudio, C., Lo Bascio, D., Martini M., Ricciardi G.P., RiccioLINo P. and Ricco, C. (2011), Repeated fluid-transfer episodes as a mechanism for the recent dynamics of Campi Flegrei caldera (1989-2010). Journal of Geophysical Research: Solid Earth (1978-2012), 116(B4).

D'Auria, L., Giudicepietro, F., Martini, M., and Lanari, R. (2012), The $4 D$ imaging of the source of ground deformation at Campi Flegrei caldera (southern Italy). Journal of Geophysical Research: Solid Earth (1978-2012), 117 (B8). 
D'Auria, L., Martini, M., Esposito, A., Ricciolino, P., and GiuDicepietro, F. (2008), A unified $3 D$ velocity model for the Neapolitan volcanic areas, In Conception, Verification and Application of Innovative Techniques to Study Active Volcanoes (ed. Marzocchi W. and Zollo A.), pp. 375-390, ISBN 978-8889972-09-0.

D'Auria, L., B. MAssa, and A. De Matteo (2014), The stress field beneath a quiescent stratovolcano: The case of Mount Vesuvius. J. Geophys. Res. Solid. Earth., 119. doi:10.1002/2013JB010792.

Deino, A.L., Orsi, G., Piochi, M. and de Vita, S. (2004), The age of the neapolitan Yellow Tuff caldera-forming eruption (Campi Flegrei caldera-Italy) assessed by 40ar/39ar dating method. Journal of Volcanology and Geothermal Research, 133, 157-170.

Del Gaudio, C., Aquino, I., Ricciardi, G. P., Ricco, C., and Scandone, R. (2010), Unrest episodes at Campi Flegrei: A reconstruction of vertical ground movements during 1905-2009. Journal of Volcanology and Geothermal Research, 195(1), 48-56.

DiETRICH, J. (1994), A constitutive law for rate of earthquake production and its application to earthquake clustering. J. Geophys. Res. 99, 2601-2618.

Di Vito, M. A., Isaia, R., Orsi, G., Southon, J., De Vita, S., D'Antonio, M., Pappalardo L. and Piochi, M. (1999), Volcanism and deformation since 12,000 years at the Campi Flegrei caldera (Italy). Journal of Volcanology and Geothermal Research, 91(2), 221-246.

Dzurisin, D. (2006), Volcano Deformation: Geodetic Monitoring Techniques. Berlin, Springer, Springer-Praxis Books in Geophysical Sciences, $441 \mathrm{p}$.

EFron, B. (1979), Bootstrap methods: Another look at the jackknife. The Annals of Statistics 7(1): 1-26.

Fialko, Y., Khazan, Y., and Simons, M. (2001), Deformation due to a pressurized horizontal circular crack in an elastic half-space, with applications to volcano geodesy. Geophysical Journal International, 146(1), 181-190.

FroHLICH, C. (1992), Triangle diagrams: Ternary graphs to display similarity and diversity of earthquake focal mechanisms, Phys. Earth. Planet. Inter., 75, 193-198.

Gaeta, F. S., Peluso, F., Arienzo, I., Castagnolo, D., De Natale, G., Milano, G., Albanese C. and Mita, D. G. (2003), A physical appraisal of a new aspect of bradyseism: The miniuplifts. Journal of Geophysical Research: Solid Earth (1978-2012), 108(B8).

Gaudiosi, G., and Iannaccone, G. (1984), A preliminary study of stress pattern at Phlegraean Fields as inferred from focal mechanisms. Bulletin volcanologique, 47(2), 225-231.

Gebauer, S., Schmitt, A.K., Pappalardo, L., Stockli, D.F., and Lovera, O.M. (2014), Crystallization and eruption ages of Breccia Museo (Campi Flegrei caldera, Italy) plutonic clasts and their relation to the Campanian ignimbrite. Contrib. Mineral. Petrol., 167: 953, doi:10.1007/s00410-013-0953-7.

GePhart, J., and Forsyth, D. (1984), An improved method for determining the regional stress tensor using earthquake focal mechanisms data: application to the San Fernando earthquake sequence. J. Geophy. Res., 89, 9305-9320.

Hippolyte, J.C., Bergerat, F., Gordon, M., Bellier, O., Espurt, N. (2012), Keys and pitfalls in mesoscale fault analysis and paleostress reconstructions, the use of Angelier's methods. Tectonophysics, doi:10.1016/j.tecto.2012.01.012.

Lee, W.H.K., and Stewart, S.W. (1981), Principles and applications of microearthquake networks. In: Advances in Geophysics, Supplement 2, Academic Press, New York, 293 pp.
Macedonio G., Giudicepietro F., D'Auria L. and Martini M. (2014), Sill intrusion as a source mechanism of unrest at volcanic calderas. J. Geophys. Res. Solid Earth, 119, doi:10.1002/ 2013JB010868.

McKenzie, D. P. (1969), The relation between fault plane solutions for earthquakes and the directions of the principal stresses, Bull. Seismol. Soc. Am. 59, 591-601.

McTigue, D. F. (1987), Elastic stress and deformation near a finite spherical magma body: Resolution of the point source paradox. Journal of Geophysical Research: Solid Earth (1978-2012), 92(B12), 12931-12940.

Michael, A. J. (1984), Determination of stress from slip data: faults and folds. J. Geophys. Res., 89, 11517-11526.

Michael, A.J. (1987), Use of Focal Mechanisms to Determine Stress: A Control Study. J. Geoph. Res., 92, 357-368.

Mogi, K. (1958), Relations between the eruptions of various volcanoes and the deformations of the ground surfaces around them. Bulletin of the Earthquake Research Institute 36, 99-134.

NeLDER, J.A. and MEAD, R. (1965), A simplex method for function minimization, Comput. J., 7, pp. 308-313.

Окара, Y. (1985), Surface deformation due to shear and tensile faults in a half-space. Bulletin of the seismological society of America, 75(4), 1135-1154.

Окара, Y. (1992), Internal deformation due to shear and tensile faults in a half-space. Bulletin of the Seismological Society of America, 82(2), 1018-1040.

Orsi, G., Civetta, L., Del Gaudio, C., De Vita, S., Di Vito, M. A., Isaia, R., S.M. Petrazzuoli, G.P. Ricciardi and Ricco, C. (1999), Short-term ground deformations and seismicity in the resurgent Campi Flegrei caldera (Italy): an example of active blockresurgence in a densely populated area. Journal of Volcanology and Geothermal Research, 91(2), 415-451.

Orsi, G., De Vita, S., and Di Vito, M. (1996), The restless, resurgent Campi Flegrei nested caldera (Italy): constraints on its evolution and configuration. Journal of Volcanology and Geothermal Research, 74(3), 179-214.

Orsi, G., Di Vito, M. A., and Isaia, R. (2004), Volcanic hazard assessment at the restless Campi Flegrei caldera. Bulletin of Volcanology, 66(6), 514-530.

Otsubo, M., A. Yамал, and A. Kubo (2008), Determination of stresses from heterogeneous focal mechanism data: An adaptation of the multiple inverse method, Tectonophysics, 457, 150-160.

Otsubo, M., Sато, K., Yамал, A. (2006), Computerized identification of stress tensors determined from heterogeneous fault-slip data by combining multiple inverse method and k-means clustering. Journal of Structural Geology, 28, 991-997, doi:10. 10106/j.jsg.2006.03.008.

Patanè, D., Privitera, E., Gresta, S., Akinci, A., Alparone, S., Barberi, G., Chiaraluce, L., Cocina, O., D'amico, S., De Gori, P., Di Grazia, G., Falsaperla, S., Ferrari, F., Gambino, S., Giampiccolo, E., Langer, H., Maiolino, V., Moretti, M., Mostaccio, A., Musumeci, C., Piccinini, D., Reitano, D., Scarfì, L., Spampinato, S., Ursino, A., and Zuccarello, L. (2003), Seismological constraints for the dike emplacement of July-August 2001 lateral eruption at Mt. Etna volcano, Italy. Annals of geophysics, 46(4), 599-608.

Pedersen, R., and Sigmundsson, F. (2004), InSAR based sill model links spatially offset areas of deformation and seismicity for the 1994 unrest episode at Eyjafjallajökull volcano, Iceland. Geophys. Res. Lett., 31(14), doi:10.1029/2004GL020368. 
Ramsay J., Lisle R. (2000), Applications of continuum mechanics in structural geology (Techniques of modern structural geology. Vol.3), 701-1061.

ReAsenberg, P. and OpPenheimer D. (1985), FPFIT, FPPLOT and FPPAGE: Fortran computer programs for calculating and displaying earthquake fault-plane solutions, US Geol. Surv., OpenFile Rept, 85-739.

Rivera, L. and Cisternas, A. (1990), Stress tensor and fault plane solutions for a population of earthquakes. Bull. Seismol. Soc. Am., 80(3): 600-614.

Rubin, A.M., Gillard, D., and Got, J.L. (1998), A reinterpretation of seismicity associated with the January 1983 dike intrusion at Kilauea volcano, Hawaii. J. geophys. Res., 103, 10003-10015.

Segall, P. (2013), Volcano deformation and eruption forecasting. Geological Society, London, Special Publications, 380, doi:10. 1144/SP380.4.

SEgall, P. (2010), Earthquake and volcano deformation. Princeton University Press.

Segall, P., Llenos, A. L., Yun, S. H., Bradley, A. M., and SyrACUSE, E. M. (2013), Time-dependent dike propagation from joint inversion of seismicity and deformation data. Journal of Geophysical Research: Solid Earth 118(11), 5785-5804.

SEN, M. K., and Stoffa, P. L. (1995), Global optimization methods in geophysical inversion. Elsevier.

Toda, S., Stein, R. S., and SAgiYA, T. (2002), Evidence from the ad 2000 Izu islands earthquake swarm that stressing rate governs seismicity. Nature, 419, 58-61.

Tramelli, A., Troise, C., De Natale, G., and Orazi, M. (2013), A New Method for Optimization and Testing of Microseismic Networks: An Application to Campi Flegrei (Southern Italy). Bulletin of the Seismological Society of America, 103(3), 1679-1691, doi:10.1785/0120120211.

Troise, C., F. Pingue, and G. De Natale (2003), Coulomb stress changes at calderas: Modeling the seismicity of Campi Flegrei (southern Italy), J. Geophys. Res., 108, 2292, doi:10.1029/ 2002JB002006, B6.

Umakoshi, K., Shimizu, H., and Matsuwo N. (2001), Volcano-tectonic seismicity at Unzen Volcano, Japan, 1985-1999. Journal of Volcanology and Geothermal Research, 112, 117-131.

Vitale, S., and Isaia, R. (2013), Fractures and faults in volcanic rocks (Campi Flegrei, southern Italy): insight into volcano-tectonic processes. International Journal of Earth Sciences, 1-19.

Wallace, R. E. (1951), Geometry of shearing stress and relationship to faulting, J.Geol., 59, 111-130.

Woo, J. Y., and Kilburn, C. R. (2010), Intrusion and deformation at Campi Flegrei, southern Italy: sills, dikes, and regional extension. Journal of Geophysical Research: Solid Earth (1978-2012), 115(B12).

Y АMAJI, A. (2000), The multiple inverse method: a new technique to separate stresses from heterogeneous fault-slip data. J. Struct. Geol., 22: 441-452.

YAMAJ, A. (2007), An Introduction to Tectonophysics: Theoretical Aspects of Structural Geology, 4-88704-135-7, Terrapub, Tokyo.

Yамал, A., and M. Отsuво (2011), Multiple Inverse Method Software Package User's Guide, Kyoto, Japan. [Avialable at http://www.kueps.kyoto-u.ac.jp/web-bs/tsg/software/mim/man_e. pdf.].

YANG, X. M., Davis, P. M., and Dieterich, J. H. (1988), Deformation from inflation of a dipping finite prolate spheroid in an elastic half-space as a model for volcanic stressing. Journal of Geophysical Research: Solid Earth (1978-2012), 93(B5), 4249-4257.

ZupPetTA, A., and SAVA, A. (1991), Stress pattern at Campi Flegrei from focal mechanisms of the 1982-1984 earthquakes (Southern Italy). Journal of Volcanology and Geothermal Research, 48(1), $127-137$. 